\section{ACCURATELY CONFIGURE TORQUE AND SPEED}

With Smart Logic Bien-Air's Optima MX2 and its MX2 micromotor guarantee perfect control, providing you with the ultimate speed and torque control.

With adjustable LED light the MX2 brushless micromotor combines perfectly with Bien-Air's Micro-Series instruments. The combined unit is $30 \%$ shorter and 23\% lighter to provide higher levels of balanced comfort with less hand fatigue experienced during longer treatments.

The MX2 is not just powerful; it also offers perfect regulation. The power is automatically

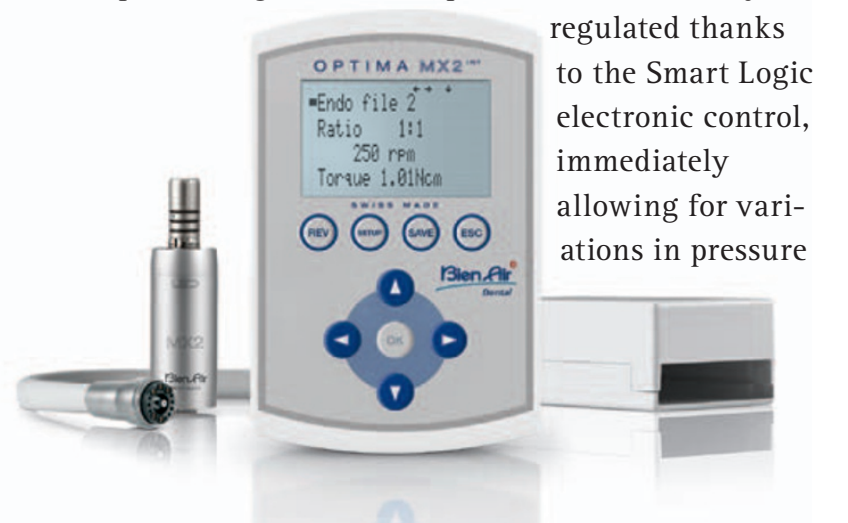

\section{HELP THROUGH EVERY LEGAL STEP}

No matter what the profession, having access to legal advice that is tailored to suit your specific needs is vital. Goodman Legal is a firm of solicitors who offer a range of services aimed directly at the dental industry.

Goodman Legal can assist with a range of services that non-specialist firms may struggle to offer, such as tailor made associate agreements. When an associate or hygienist joins a practice it is extremely important that the terms of their appointment are not only documented by a 'verbal contract' but that a formal written agreement is prepared, agreed and signed by the parties. Goodman Legal is able to draw even during complex treatments such as endodontics, prophylaxis and restorative procedures. The MX2 offers a level of safety second to none thanks to the subtle control of the tool's speed of rotation, automatically managing the reversal of the direction of rotation. The torque and speed can easily be accurately configured meaning that just two instruments are needed to carry out your procedures, saving you time and hassle.

Thanks to the ball bearings that are lubricated for life, the MX2 is maintenance free and fully sterilisable.

For further information on the Optima MX2 and micromotor contact Bien-Air on 01293550 200 or visit www.bienair.com.

up a comprehensive associate agreement that will benefit both parties, offering legal protection and clarifying the conditions of engagement.

For legal assistance from a knowledgeable and specialist law firm choose Goodman Legal. Their team of solicitors will help you take every step in the right direction.

For more information call 01517070090 or email jmg@ goodmanlegal.co.uk.

www.goodmanlegal.co.uk

\title{
THE OPTIMUM AMOUNT OF WHITENING GEL
}

Expand the range of whitening options you can offer your patients with Professional Whitening Strips from WhiteWash Laboratories.

WhiteWash Professional Whitening Strips are mouldable plastic strips containing the optimum amount of whitening gel to simply, safely, and effectively, whiten teeth. These are available in two varieties: low sensitivity 4\%, and premium 6\% Professional Whitening Strips for an even whiter smile.
WhiteWash Professional Whitening Strips can be used in conjunction with regular tray whitening, or as a 'top up' to more advanced in-surgery whitening techniques. WhiteWash Professional Whitening Strips also provide excellent value for money for the patient, and as such are a great 'first step' for patients keen to try whitening for the first time.

To learn more about how your practice can benefit from a range of cost-effective whitening solutions, contact WhiteWash Laboratories on 08446869150 or visit www.whitewashstrips.com.

\section{HEALTH WARNING FOR DENTAL PRACTICES}

Business intelligence company Plimsoll has issued a health warning for dental practices. Plimsoll's study into the financial health of the United Kingdom's largest 471 dental practice companies has revealed as many as 158 need an urgent survival plan, either from an injection of capital, a radical cost reduction scheme or financial restructuring, if they're to continue to trade.

Plimsoll investigated the overall financial performance of each of the UK's leading dental practice companies and scored each on their financial health. Each company was given a rating of either 'strong', 'good', 'mediocre', 'caution' or 'danger'.

The 158 dental practice companies given a 'danger' rating were found to be operating under financial pressure and many of them 'risked being forced out of the market'. Forty-one companies were given a 'caution' rating; 35 a 'mediocre' rating; 40 'good'; and 197 a 'strong' rating.

According to Plimsoll, a failing company typically shows the following characteristics: a fall in sales relative to investment; a decline in profitability relative to investment; an increase in total debts; a fall in shareholder equity; and an increase in the exposure of creditors.

For more information on the Dental Practices report contact Chris Glancey on 01642626419 or email c.glancey@plimsoll.co.uk. $B D J$ readers are entitled to a $£ 50$ discount off the cost of the report by calling 01642 626419 and quoting reference PR/HC09. 